\title{
Landscape designers development based on Personal knowledge management and collaboration
}

\author{
Long Yan \\ College of Urban Construction, Wuhan University of Science and Technology, Wuhan \\ E-mail:L020009@163.com
}

Keywords: Landscape designers; Occupational quality; Expected abilities

\begin{abstract}
More complicated problems demand collaborative innovation. Accordingly, key growth factors for landscape designers' skills are personal knowledge management and collaborative abilities. So, design education occurs not only in school but also after school. Knowledge management and the collaborative ability of landscape designers will be part of the development of occupational skills and quality. Paying more attention to the occupational quality of landscape designers will reduce the discrepancy between a university education and the expected abilities of landscape designers from enterprises and the job market.
\end{abstract}

\section{Introduction}

Designing requires proper organisation and skills to solve problems. landscape designers solving problems are inclined to an engineering approach using basic engineering knowledge, personal qualities of engineers, interpersonal teamwork and engineering system knowledge. The industrial development of China during this period of rapid economic and social development requires large numbers of quality landscape designers. The rapid development of technological industries encourages young landscape designers to keep their knowledge up-to-date. In addition, with the development of mobile Internet technology, there is also a stress on teamwork collaboration and the communication skills of landscape designers.

The popularity of mobile Internet technology has important effects on the personal occupational development of landscape designers concerning knowledge management and knowledge co-ordination, particularly during the early years of their professional employment. Knowledge management and knowledge co-ordination are required qualities of professional landscape designers. In aiming at the early phase of graphic, industrial and interaction landscape designers in professional careers, the research reported in this article features the use of questionnaires and auxiliary user interviews to analyse the knowledge management of landscape designers. It identifies the essential qualities of landscape designers as they develop their personal knowledge management. These include project control, individual performance and display of work. Individual performance and personal knowledge co-ordination, with occupational design characteristics, are preconditions for the successful designer. There are demands from the nature of work and, as individuals develop, they promote the flow of hidden knowledge in the design field, which translates into design ability.

\section{Designer Knowledge Systems}

The knowledge in design companies or departments is often based on procedures. Hence, this knowledge shows how to carry out the processes in a project or in organisational supply chains. In early practice, knowledge management was passive, did not take account of the human factor and ignored the need to add new knowledge . The design field is a business that involves undertaking projects. Project and product management is thought of highly by design management, but there is a lack of knowledge management for individuals. With the importance of collaboration leading to innovation on complicated scientific knowledge systems, the development of individual knowledge systems is increasingly seen as a critical factor influencing team innovation. Although, competition is an effective approach to motivating students with advanced programming skills.

Separate from the schedule management of a project, the landscape designers' individual knowledge systems concentrate on personal knowledge management and innovation, and 
occupational development (see Figure 1). Projects or products are primary content in the individual knowledge system. Hence, design management is a precondition of a designer's individual knowledge management system. Individual growth by self-study is an important occupational quality. For collaborative innovation requirements, individuals will have only partial knowledge as part of personal development. From the perspective of innovation quality, individual knowledge systems contain personal knowledge management, except for industrial skill definitions, and even include knowledge collaboration.

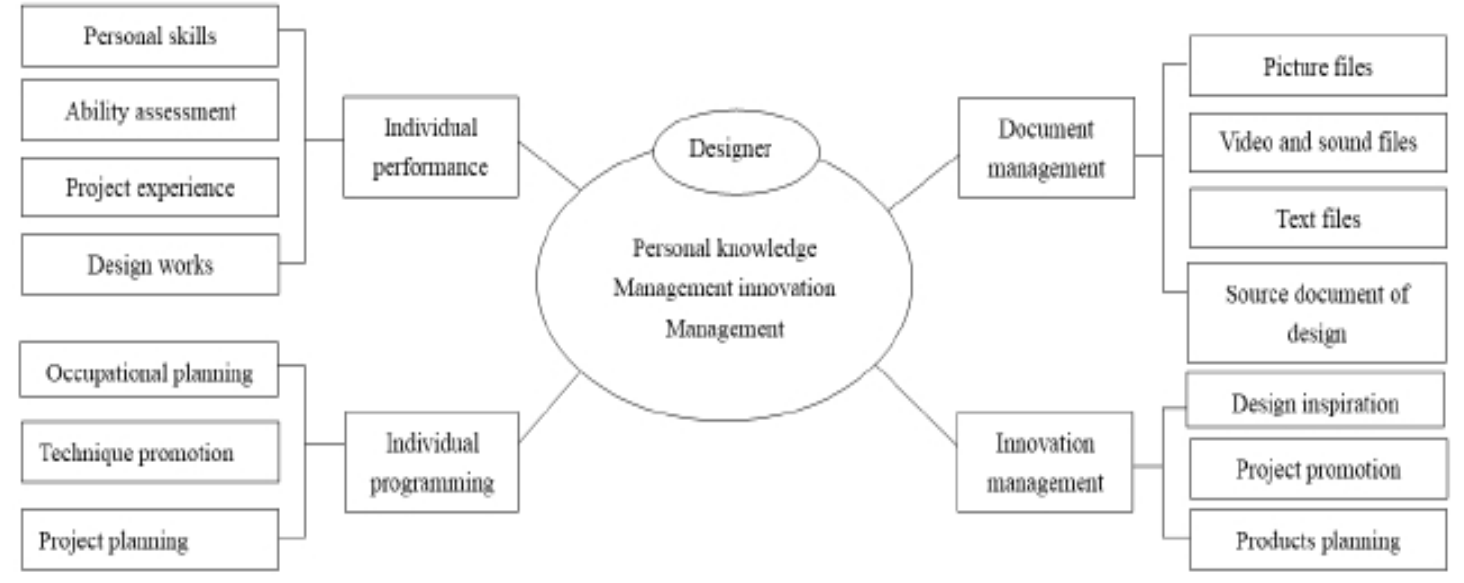

Figure 1 Knowledge system for landscape designers.

In this paper, Hanaki Created the evolution of the social network on the cooperation model (WHP) model in 2007 to simulate the real dynamic Guest to enterprise knowledge coordination network structure, network nodes represent the customers, employees in the two kinds of main body of knowledge, knowledge collaborative relationship between edge on behalf of the principal,Set $C=\{1, \ldots, N\}$ as body,$U \in C$ as the enterprises involved in knowledge in the collection of employees, $V \in C$ as collection of customers to participate in the enterprise service innovation. For any define variables $i, j \in c$, if $\mathrm{i}$, the link between $\mathrm{j}, . \xi(i, j)=1$, In this paper, on the investigation to the knowledge coordination performance, in addition to the inspection index, and cooperation.Used to depict the particular moment, the main body of a total of $\mathrm{N}$ in the network, take positive knowledge collaborative strategy $\mathrm{C}$ individual proportion in $N_{c}(t)$, formula as follows:

$$
p_{c}(t)=\frac{N_{c}(t)}{N}
$$

\section{Personal Knowledge Management of Landscape Designers}

In actual work, landscape designers often participate in several projects at the same time. Only $16 \%$ of the sample participated in one project at the same time, $41 \%$ in two, $35 \%$ in three and $8 \%$ in four or more projects at the same time. Hence, the norm is for landscape designers participating in 2-3 projects, while four or more would be in a high stress environment. It would be expected, that those simultaneously participating in four or more projects would be senior employees. the orange line shows that the number of projects increases with seniority. The blue line indicates that, with more experience, landscape designers are less likely to participate in only one project. Thus, project quantity is a simple and direct measure of work pressure. More skilful landscape designers participate in more projects, which also means more work pressure and responsibility.

\section{Document Management}

Participating in several projects requires project documents for landscape designers. File management is one of the important components of individual knowledge management for landscape designers, as indicated in Figure 1. Results of the questionnaires show that over $86 \%$ of project teams regulate the names of files, as shown in Figure 2.there is document confusion on close 
to $73 \%$ of projects, including some confusion on $69 \%$ and much confusion on $4 \%$ of projects. Thus, despite clear regulations on nominated names there is still document confusion. Document management of a project is important for design management and project control.

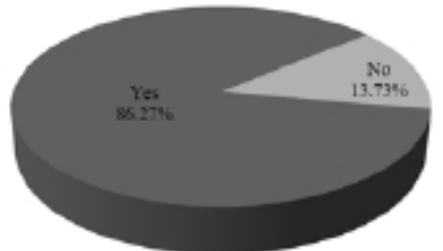

Figure 2: Nominated file names for projects.

\section{The Design Enterprise}

The design enterprise is organised as individual-team-department-enterprise. However, the development of information technology and changing market requirements generate a new requirement for a flatter, more agile structure. Emphasis on knowledge collaboration is an important way to integrate and balance these requirements. Basically speaking, design is a creative activity and so creative ability is one of the necessary qualities of a designer.

As China develops into an advanced economy, innovation shall be at the heart of its industrial economy. Innovation promotes the collaborative integration between the design industry and the manufacturing industry. landscape designers are aware of this trend, which is supported by knowledge collaboration.

\section{Hidden knowledge}

Hidden knowledge is very important and plays an indispensable role in design, and even becomes a necessary part of the individual knowledge system for landscape designers. Innovation inspiration, design thinking and creativity all accumulate with long-term design experience. Study of these types of knowledge at school is limited by the environment, resources and methods and so, these kinds of knowledge are acquired during actual work. With the development of knowledge collaboration, hidden knowledge can be shared by landscape designers through communicating, i.e. by chatting, observing, simulating and practising. In addition, these personnel acquire knowledge from the external environment through various channels .

\section{Designer Knowledge}

The results show that about 22\% of landscape designers frequently face the problem of not understanding the system they are using. The update of design software makes the compatibility problem more unavoidable. As for addressing this problem, there is a phenomenon known in which landscape designers with short working experience will first choose to gain knowledge of the relevant software, e.g. instant message apps QQ, Weixin. In the process, hidden knowledge is transmitted .

Landscape designers with longer working seniority are better at exploration and working by themselves. If they need external help, they could rapidly find an efficient way of obtaining it, e.g. from a forum or circle of friends. landscape designers of new products gain invisible knowledge through long-term practice and study, especially invisible processing knowledge.

Hidden knowledge flows in collaborations. With increased working seniority, hidden knowledge gets transferred to obvious knowledge, and individual experience becomes occupational common sense. In this process, knowledge collaboration promotes the flow of hidden knowledge and becomes the necessary essence of landscape designers during their early experience as a designer.

\section{CONCLUSIONS}

Knowledge management promotes design talent in professional landscape designers in the actual 
design environment. A successful project needs a good design team, with the designer as the key component. When facing challenges of how to creatively solve realistic problems, knowledge collaboration becomes a necessary occupational quality. With the development and promotion of individual quality, knowledge collaboration is also a reflection of the development of knowledge management. The rapid development of information technology provides more channels or platforms for knowledge and knowledge collaboration.

A designer during the early stages in the occupation should consciously use these tools to promote the improvement of their personal knowledge, in order to satisfy occupational quality requirements. Individuals should collaborate with knowledge integration across the whole design group or enterprise organisation, to improve the occupational role of landscape designers.

\section{REFERENCE}

[1] Alam I. An exploratory investigation of user involvement in new service development[J].Journal of the Academy of Marketing Science.2002.30(3) :250.

[2].Ulwick A W. Turn customer input into innovation [J].Harvard Business Review.2002.80(1) :91-98.

[3]. Matthing J, Sanden B, Edvardsson B. New service devel-opment:learning from and with customers[J].Interna-tional Journal of Service Industry Management.2004.15 (5) :479- 498.

[4].Nagurney A.Qiang Q. A knowledge collaboration net-work model across Disciplines.[J].Advances in Social Computing.2010:138-148.

[5].Kim H, Park Y.Structure effects of R\&D collaboration network on knowledge diffusion performance[J].Expert Systems with Applications.2009.36(5) :8986-8992.

[6].Newman M E J.Scientific collaboration networks.Network construction and fundamental results.[J].Physical review E.2001.64(1) :1613. 
